\title{
Large heterometallic coordination cages with gyrobifastigium-like geometry
}

Received 00th January 20xx, Accepted 00th January 20xx

DOI: $10.1039 / x 0 x \times 00000 x$

\author{
Giacomo Cecot, ${ }^{a}$ Bassam Alameddine, ${ }^{b}$ Stéphanie Prior, ${ }^{a}$ Rita De Zorzi, ${ }^{c}$ Silvano Geremia, ${ }^{c}$ Rosario \\ Scopelliti, ${ }^{a}$ Fadaei T. Farzaneh, ${ }^{a}$ Euro Solari, ${ }^{a}$ and Kay Severin*a
}

www.rsc.org/

Large $\left(M_{w}>10 \mathrm{kDa}\right)$ heterometallic coordination cages with gyrobifastigium-like geometry are obtained by using metalloligands with sterically demanding Fe" clathrochelate cores and four divergent pyridyl groups. Upon reaction with cis-blocked $\mathrm{Pt}^{\prime \prime}$ and Pd" complexes, $\mathrm{M}_{8}{ }_{8} \mathrm{~L}_{4}$ cages are formed. The gyrobifastigium geometry of these cages is in contrast to the barrel-like structures which are typically observed for metallasupramolecular assemblies with $\mathrm{M}_{8} \mathrm{~L}_{4}$ stoichiometry.

A polyhedron with gyrobifastigium geometry contains eight vertices, fourteen edges, and four regular triangles plus four squares as faces (Fig. 1, A). It is formed by joining two triangular prisms along their square sides, with one prism being rotated by $90^{\circ}$ with respect to the other. The gyrobifastigium is member number 26 of the group of Johnson solids. This group contains all non-uniform, strictly convex polyhedral which are based on regular faces (92 in total). ${ }^{1}$ They complement the highly symmetric Platonic and Archimedean solids and the prisms and antiprisms. The gyrobifastigium geometry is rarely observed in chemistry. ${ }^{1-8}$ Examples of compounds with this geometry include octanuclear lithium ${ }^{3}$ and copper clusters, ${ }^{4}$ derivatives of tricycle[3.3.0.03.7] ("stellane") ${ }^{5}$ or pentacyclo[3.3.0.0 $0^{2 \cdot 4} \cdot 0^{3.7} \cdot 0^{6.8}$ ]octane ("cuneane"), ${ }^{6}$ the $\mathrm{Hg}_{4}\left(\mathrm{Se}_{2}\right)_{2}$ core of the anion $\left[\mathrm{Hg}_{4}\left(\mathrm{Se}_{2}\right)_{2}\left(\mathrm{PSe}_{4}\right)_{4}\right]^{8-, 7}$ and the $\mathrm{As}_{4} \mathrm{~S}_{4}$ molecules in the mineral realgar. ${ }^{8,9}$ To the best of our knowledge, there is only one example of a metallasupramolecular structure with an approximate, highly distorted gyrobifastigium arrangement of the metal ions, and that is an octanuclear $\mathrm{Ni}_{8} \mathrm{~L}_{12}$ cage described by Stephenson and Ward. ${ }^{10}$ This complex displays the

a. Institut des Sciences et Ingénierie Chimiques, École Polytechnique Fédérale de Lausanne (EPFL), 1015 Lausanne, Switzerland

b. Department of Mathematics and Natural Sciences, Gulf University of Science \& Technology (GUST), Kuwait

c. Centro di Eccellenza in Biocristallografia, Dipartimento di Science Chimiche e Farmaceutiche, Università di Trieste, Trieste, Italy

*E-mail: kay.severin@epfl.ch.

+ Electronic Supplementary Information (ESI) available: experimental details and analytical data. See DOI: 10.1039/x0xx00000x connectivity found for cuneane, and the fact that only twelve of the fourteen edges are connected results in a large deviation from the gyrobifastigium geometry with a change of point symmetry from $D_{2 \mathrm{~d}}$ to $C_{2 \mathrm{v}}$.

Coordination cages with more regular gyrobifastigium geometry can - in principle - be formed by a paneling approach using face-capping tetratopic donor ligands in combination with ditopic metal receptors (Fig. 1, B). However, the $M_{8} L_{4}$ assemblies reported to date have barrel- or tube-like structures with square prismatic geometry (Fig. 1, C). ${ }^{11,12}$ We describe herein the synthesis and the structural characterization of $\mathrm{Pt}^{\prime \prime} \mathrm{L}_{4}$ and $\mathrm{Pd}_{8}{ }_{8} \mathrm{~L}_{4}$ coordination cages with gyrobifastigium-like geometry. The cages are based on novel metalloligands containing inert Fell clathrochelate complexes at their core.

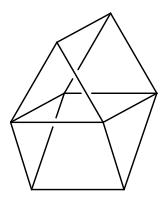

A

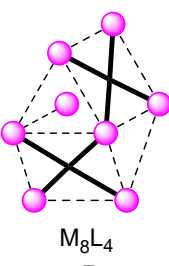

B gyrobifastigium

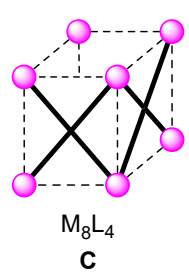

square prism

Fig. $1 \mathrm{~A}$ polyhedron with gyrobifastigium geometry and schematic representations of octanuclear coordination cages with gyrobifastigium or square prismatic geometry. The bold lines represent tetratopic ligands and the pink spheres represent the metal ions at the vertices. Two tetratopic ligands paneling background faces have been omitted for clarity.

Functionalized clathrochelate complexes have recently emerged as a promising new class of metalloligands for applications in supramolecular coordination chemistry and materials science. ${ }^{13,14}$ Mononuclear clathrochelate complexes with diamagnetic $\mathrm{Fe}^{\text {ll }}$ centers can be obtained by one-pot reactions of $\mathrm{FeCl}_{2}$ with a dioxime ligand and boronic acids. ${ }^{13}$ The incorporation of functional groups is possible by using functionalized boronic acids (e.g. pyridylboronic acid). ${ }^{13,15}$ An interesting property of $\mathrm{Fe}^{\text {ll }}$ clathrochelate complexes is their 
high chemical stability. This feature enabled us to perform cross-coupling reactions between two different clathrochelate complexes, allowing the synthesis of long, rigid-rod type complexes. ${ }^{13 e}$

We hypothesized that it should be possible to prepare tetrapyridyl metalloligands by $\mathrm{Pd}$-catalyzed cross-coupling of brominated clathrochelate complexes with pyridylboronic acid. We therefore synthesized the clathrochelates $\mathbf{1}$ and $\mathbf{2}$ by reaction of $\mathrm{FeCl}_{2}$ with 3,5-dibromophenylboronic acid and dimethyl- or diethylglyoxime (Scheme 1, for details see ESI). The subsequent four-fold cross-coupling reaction with pyridylboronic acid in the presence of $\mathrm{Pd}_{2}(\mathrm{dba})_{3}, \mathrm{SPhos}^{16}$ and $\mathrm{K}_{3} \mathrm{PO}_{4}$ was remarkably clean, allowing the isolation of the tetratopic metalloligands $\mathbf{3}$ and $\mathbf{4}$ in good yields.
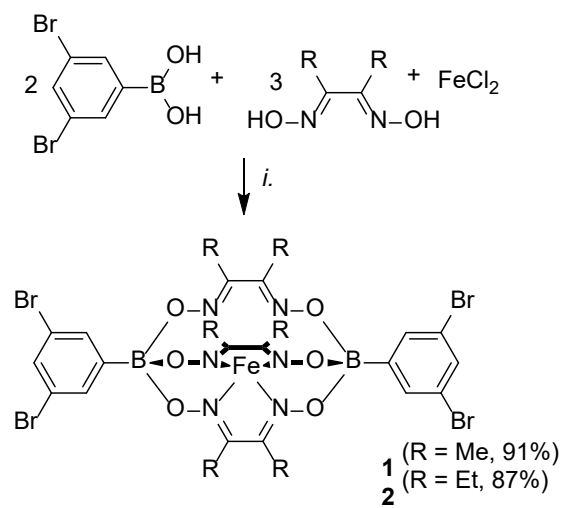

$\downarrow i i$

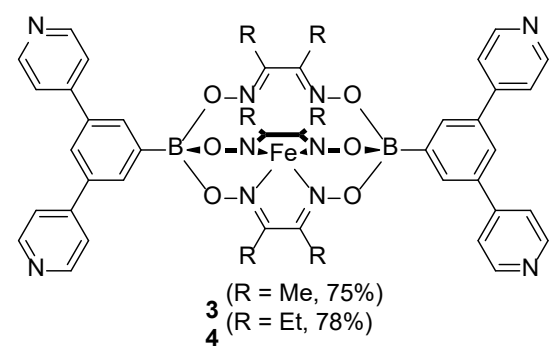

Scheme 1 Synthesis of the tetratopic metalloligands 3 and 4 . Reagents and conditions: i. $\mathrm{MeOH}, 70^{\circ} \mathrm{C}, 4$ h; ii. 1 or 2 (1 eq.), 4-pyridylboronic acid (8 eq.), $\mathrm{K}_{3} \mathrm{PO}_{4}$ (8 eq.), $\mathrm{Pd}_{2}(\mathrm{dba})_{3}$ (0.2 eq.), SPhos (0.4 eq.), toluene/nBuOH $1: 1,87^{\circ} \mathrm{C}, 4 \mathrm{~d}$.

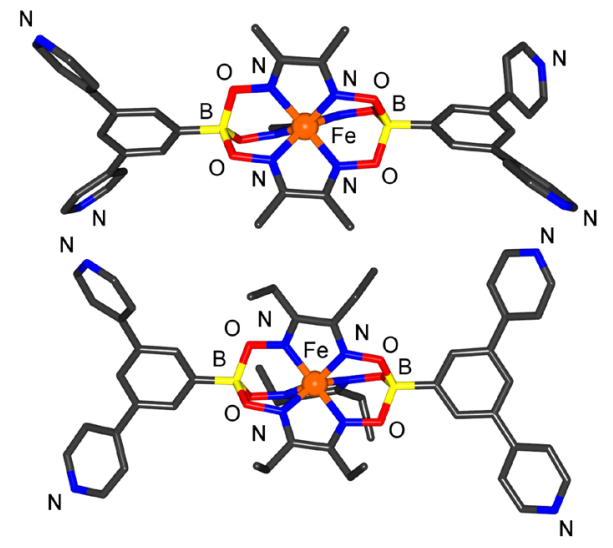

Fig. 2. Molecular structures of clathrochelate-based tetrapyridyl ligands $\mathbf{3}$ and $\mathbf{4}$ as determined by X-ray crystallography. Color coding: C: gray, B: yellow, Fe: orange, N: blue, $\mathrm{O}$ : red. Hydrogen atoms and solvent molecules are omitted for clarity.

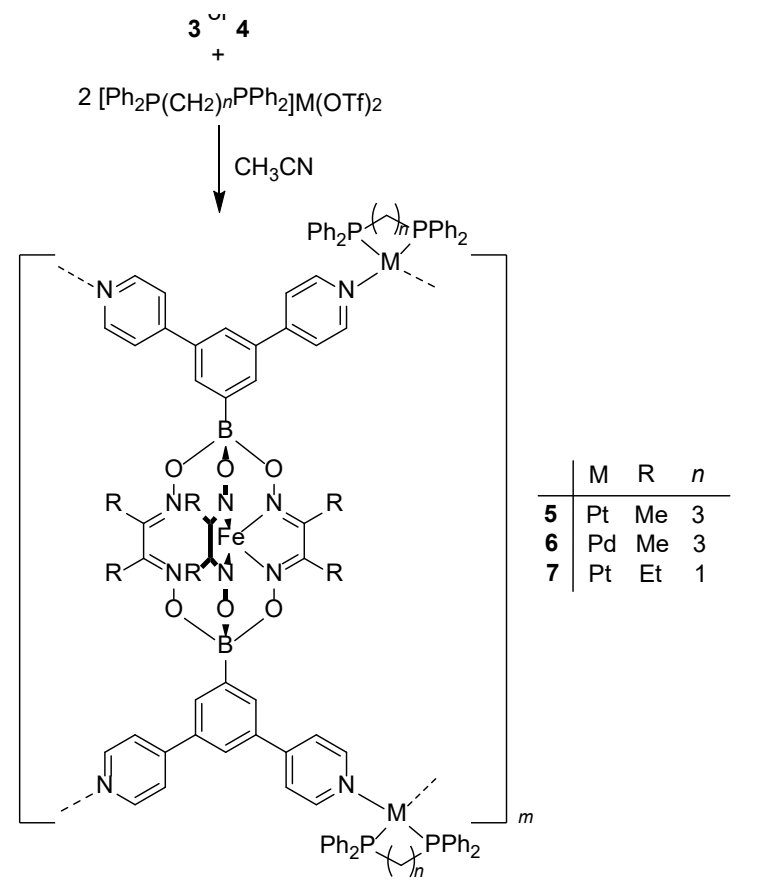

Scheme 2 Synthesis of the coordination cages 5-7. Conditions: $\mathrm{CH}_{3} \mathrm{CN}, 50^{\circ} \mathrm{C}, 1.5 \mathrm{~h}$

The molecular structures of the tetrapyridyl ligands $\mathbf{3}$ and $\mathbf{4}$ were analyzed by single crystal X-ray diffraction (Fig. 2). The clathrochelate cores of $\mathbf{3}$ and $\mathbf{4}$ display the usual distorted trigonal prismatic coordination at the Fell center, and the average Fe- $\mathrm{N}$ bond distance is $1.90 \AA$. This value is within the expected range.

Next, we have examined whether the new metalloligands 3 and 4 could be used for the assembly of a cage-like structure. As reaction partner, we chose the cis-blocked $\mathrm{Pt}^{\mathrm{I}}$ and $\mathrm{Pd}^{\prime \prime}$ complexes $\left[\mathrm{Ph}_{2} \mathrm{P}\left(\mathrm{CH}_{2}\right)_{n} \mathrm{PPh}{ }_{2}\right] \mathrm{M}(\mathrm{OTf})_{2}(\mathrm{M}=\mathrm{Pt}, \mathrm{Pd}, n=1,3)$. Based on literature reports, we expected that the combination of these building blocks would give prismatic, barrel-like structures with the stoichiometry $\mathrm{M}_{6} \mathrm{~L}_{3}$ or $\mathrm{M}_{8} \mathrm{~L}_{4}{ }^{11,17}$

The addition of deuterated acetonitrile to a mixture of metalloligand 3 and two equivalents of the $\mathrm{Pt}$ " complex $(\mathrm{dppp}) \mathrm{Pt}(\mathrm{OTf})_{2} \quad(\mathrm{dppp}=1$ 1,3-bis(diphenylphosphino)propane) resulted in the formation of a clear solution (reaction time: $1.5 \mathrm{~h}, \mathrm{RT}$ ), even though ligand $\mathbf{3}$ is poorly soluble in this solvent. Work-up allowed the isolation of complex $\mathbf{5}$ in $96 \%$ yield. Analysis of the product by NMR spectroscopy $\left(\mathrm{CD}_{3} \mathrm{CN}\right)$ suggested the formation of a defined assembly. The ${ }^{1} \mathrm{H} N M R$ spectrum was rather simple, revealing the formation of a highly symmetrical structure, and the DOSY spectroscopy indicated the presence of a single, large aggregate with a uniform diffusion constant. The mass spectrum of complex $\mathbf{5}$ showed prominent peaks at $\mathrm{m} / \mathrm{z}=2543.35$ and 2004.89 which can be attributed to $\left[\{(\mathrm{dppp}) \mathrm{Pt}\}_{8}(3)_{4}(\mathrm{OTf})_{12}\right]^{4+}$ and $\left[\{(\mathrm{dppp}) \mathrm{Pt}\}_{8}(3)_{4}(\mathrm{OTf})_{11}\right]^{5+}$, respectively. However, the ${ }^{31} \mathrm{P} N \mathrm{NMR}$ spectrum of the product was puzzling as it showed two singlets 
of equal intensity. For a barrel-like $\left[\mathrm{Pt}_{8}(3)_{4}\right]^{16+}$ structure with tetragonal prismatic geometry, one would expect only one signal in the ${ }^{31} \mathrm{P}$ NMR spectrum, since all phosphorous atoms would be magnetically equivalent.

We have explored two other combinations: metalloligand 3 and the cis-blocked $\mathrm{Pd}^{\prime \prime}$ complex (dppp)Pd(OTf) $)_{2}$, as well as metalloligand 4 and the $\mathrm{Pt}^{\prime \prime}$ complex $(\mathrm{dppm}) \mathrm{Pt}(\mathrm{OTf})_{2}(\mathrm{dppm}=$ 1,3-bis(diphenylphosphino)methane). A similar behaviour was observed: the reactions gave rise to defined products ( 6 and 7 , Scheme 2), and analysis by mass spectrometry suggested the formation of $\left[\mathrm{M}_{8}{ }_{8} \mathrm{~L}_{4}\right]^{16+}$ complexes. But as it was observed for complex 5, the ${ }^{31} \mathrm{P}$ NMR spectra of $\mathbf{6}$ and $\mathbf{7}$ showed two peaks instead of the anticipated singlet.

A crystallographic analysis of complex $\mathbf{5}$ provided an explanation for the unexpected NMR data: instead of a barrel structure, the assembly displays an unusual gyrobifastigium-like geometry (Fig. 3). The connectivity of complex $\mathbf{5}$ corresponds to what is schematically depicted in Fig. 1B. The ligands panel the four rectangular faces, and the Pt atoms occupy the vertices of a distorted gyrobifastigium. The open triangular faces represent approximate isosceles right triangles. As a result of the rectangular geometry of the bridging ligand, we observe eight short Pt...Pt distances ranging from 13.1 to $13.8 \AA$, and six long Pt...Pt distances ranging from 18.6 to $19.9 \AA$. The difference between short and long Pt...Pt distances accounts for the deviation from a perfect gyrobifastigium geometry, because the edges of the latter have equal length. It should be noted, however, that the $D_{2 \mathrm{~d}}$ symmetry is approximately conserved.

Complex 5 features two magnetically different (dppp)Pt complexes since a gyrobifastigium has four vertices connecting three faces and four other vertices connecting four faces. The structure is thus in line with the ${ }^{31} \mathrm{P}$ NMR spectrum of 5, which shows two singlets of equal intensity. We assume that the complexes $\mathbf{6}$ and $\mathbf{7}$ adopt a similar geometry.

With regard to potential host-guest chemistry, one should note that complex $\mathbf{5}$ appears to be less suited for tight encapsulation of guests because the empty triangular faces represent large openings. Furthermore, the central part of the structure is occupied to a large extent by the dimethyldioximato groups of the Fe clathrochelate complexes.

The steric demand of the clathrochelate complexes appears to be a likely reason of why we observe a gyrobifastigium-like geometry instead of a more common square-prismatic barrel structure. The Fe $\cdots$ Fe distances can be used as an indication of the steric interactions between the clathrochelate complexes. For complex 5, the Fe atoms are arranged in the form of a distorted tetrahedron, and one can observe two short $\mathrm{Fe} \cdots \mathrm{Fe}$ distances of 9.4 and $10.3 \AA$, and four long Fe...Fe distances between 12.2 and $12.3 \AA$. The short Fe $\cdots$ Fe distances are found for ligands occupying rectangular faces which share a common edge. The planes of the rectangles with a common edge cross at angles of $89^{\circ}$, which is very close to the $90^{\circ}$ angle of a hypothetical square prismatic structure. A square prism is thus expected to show exclusively short $\mathrm{Fe}$-..Fe distances, corresponding to a sterically less favorable situations (for a more detailed discussion see ESI).
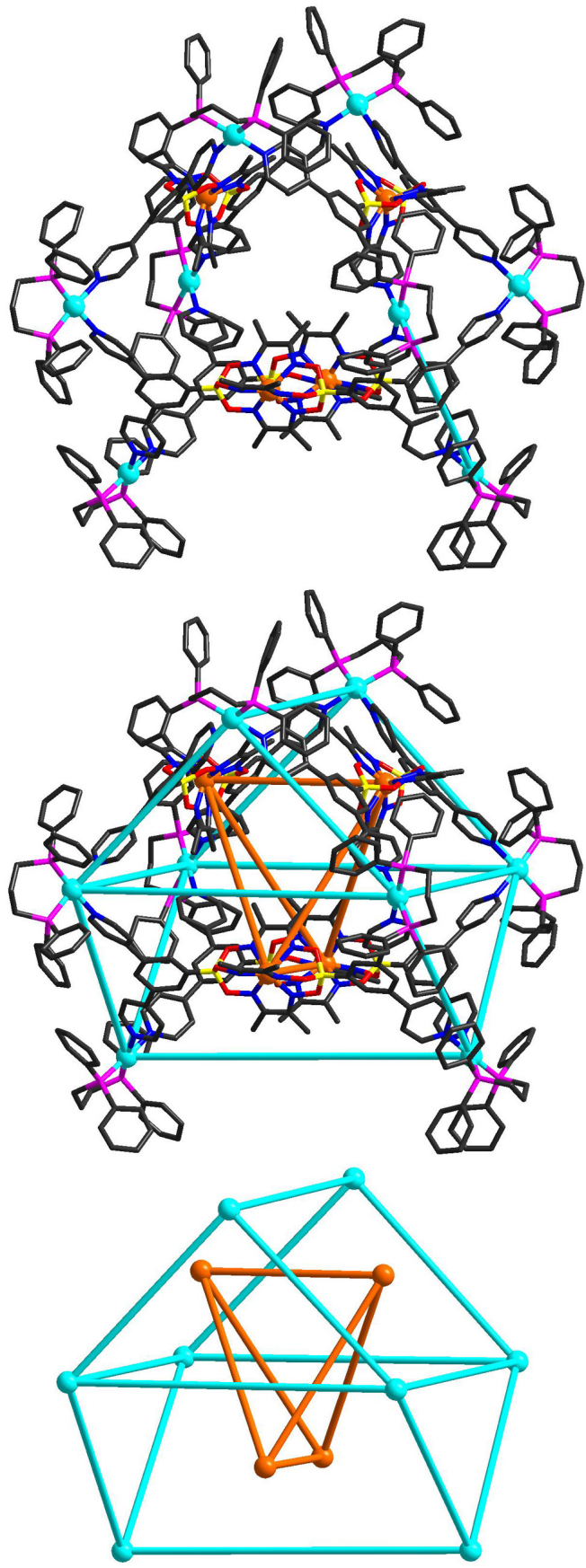

Fig. 3. Molecular structure of cage $\mathbf{5}$ in the crystal. The gyrobifastigium-like arrangement of the Pt atoms and the distorted tetrahedral arrangement of the Fe

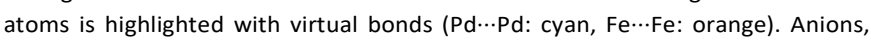
hydrogen atoms and solvent molecules are not shown for clarity. Color coding: $\mathrm{C}$ : gray, Pt: cyan, Fe: orange, P: purple, O: red, B: yellow, N: blue.

In conclusion, we have reported the synthesis of novel metalloligands with four divergent pyridyl groups and iron clathrochelate complexes at the core. The combination of these ligands with cis-blocked $\mathrm{Pt}^{\prime \prime}$ or $\mathrm{Pd}^{\prime \prime}$ complexes gives $\mathrm{M}_{8}{ }_{8} \mathrm{~L}_{4}$ coordination cages with uncommon gyrobifastigium-like geometry. Steric interactions between the metalloligands appear to be the driving force for the formation of these unusual structures, because a square prismatic arrangement of 
the $\mathrm{M}_{8}{ }_{8} \mathrm{~L}_{4}$ complexes would lead to a more compressed packing of the large central parts of the metalloligands. Overall, our results represent further evidence that metalloligands based on clathrochelate complexes are versatile building blocks for structural supramolecular chemistry, and that the steric demand of the clathrochelates can be a decisive factor for controlling the size $\mathrm{e}^{13 a}$ and the geometry of a metallasupramolecular assembly.

The work was supported by the Kuwait Foundation for the Advancement of Sciences (KFAS, P314-34SC-01, B.A.), by the Swiss National Science Foundation, by the Marie Curie Initial Training Network "ReAD", and by the Ecole Polytechnique Fédérale de Lausanne (EPFL). We thank Dr. Daniel Ortiz Trujillo for the MS measurements.

\section{Notes and references}

1 S. Alvarez, Dalton Trans., 2005, 2209.

2 D. Casanova, M. Llunell, P. Alemany and S. Alvarez, Chem. Eur. J., 2005, 11, 1479.

3 (a) T. M. Konrad, K. R. Grünwald, F. Belaj, N. C. Mösch-Zanetti and Inorg. Chem., 2009, 48, 369; (b) T. Koch, S. Blaurock, F. Somoza Jr. and E. Hey-Hawkins, Eur. J. Inorg. Chem., 2000, 2167.

4 (a) W.-P. Leung, Y.-C. Chan and T. C. W. Mak, Dalton Trans., 2014, 43, 63; (b) J. Besinger and D. Fenske, Z. Anorg. Allg. Chem., 2001, 627, 1487.

5 C. Ayats, P. Camps, M. D. Duque, M. Font-Bardia, M. R. Muñoz, X. Solans and S. Vázquez, J. Org. Chem., 2003, 68, 8715.

6 H. Irngartinger, S. Strack, R. Gleiter and S. Brand, Acta Cryst. C, 1997, C53, 1145.

7 K. Chondroudis and M. Kanatzidis, Chem. Commun. 1997, 401.

8 E. J. Porter and G. M. Sheldrick, J. Chem. Soc., Dalton Trans. 1972, 1347.

9 Most of the compounds cited in refs. 3-8 display only approximate gyrobifastigium geometry, and not all edges of the polyhedron are represented by bonds.

10 A. Stephenson and M. D. Ward, Dalton Trans., 2011, 40, 7824.

11 (a) J. Yang, M. Bhadbhade, W. A. Donald, H. Iranmanesh, E. G. Moore, H. Yan and J. E. Beves, Chem. Commun., 2015, 51, 4465; (b) B. Roy, A. K. Ghosh, S. Srivastava, P. D'Silva and P. S Mukherjee, J. Am. Chem. Soc., 2015, 137, 11916; (c) S. Goeb, S. Bivaud, V. Croué, V. Vajpayee, M. Allain and M. Sallé, Materials, 2014, 7, 611; (d) Y. Yamanoi, Y. Sakamoto, T. Kusukawa, M. Fujita, S. Sakamoto and K. Yamaguchi, J. Am. Chem. Soc., 2001, 123, 980.

12 (a) W. Meng, A. B. League, T. K. Ronson, J. K. Clegg, W. C. Isley, D. Semrouni, L. Gagliardi, C. J. Cramer and J. R. Nitschke, J. Am. Chem. Soc., 2014, 136, 3972; (b) W. Meng, J. K. Clegg and J. R. Nitschke, Angew. Chem. Int. Ed., 2012, 51, 1881.

13 Mononuclear clathrochelate complexes as metalloligands: $(a)$ S. Jansze, G. Cecot, M. D. Wise, K. O. Zhurov, T. K. Ronson, A. M. Castilla, A. Finelli, P. Pattison, E. Solari, R. Scopelliti, G. E. Zelinskii, A. V. Volgzhanina, Y. Z. Voloshin, J. R. Nitschke and K. Severin, J. Am. Chem. Soc., 2016, 138, 2046; (b) A. Ardavan, A. M. Bowen, A. Fernandez, A. J. Fielding, D. Kaminski, F. Moro, C. A. Muryn, M. D. Wise, A. Ruggi, E. J. L. Mclnnes, K. Severin, G. A. Timco, C. R. Timmel, F. Tuna, G. F. S. Whitehead, R. E. P. Winpenny, npj Quant. Inf., 2015, 1, 15012; (c) M. D. Wise, J. J. Holstein, P. Pattison, C. Besnard, E. Solari, R. Scopelliti, G. Bricogne and K. Severin, Chem. Sci, 2015, 6, 1004; (d) Y.-Y. Zhang, Y.-J. Lin and G.-X. Jin, Chem. Commun., 2014, 50, 2327 (e) M. D. Wise, A. Ruggi, M. Pascu, R. Scopelliti and K. Severin, Chem. Sci., 2013, 4, 1658.
14 Dinuclear clathrochelate complexes as metalloligands: (a) M. Marmier, G. Cecot, B. F. Curchot, P. Pattison, E. Solari, R. Scopelliti and K. Severin, Dalton Trans., 2016, 45, 8422; (b) M. Marmier, M. D. Wise, J. J. Holstein, P. Pattison, K. Schenk, E. Solari, R. Scopelliti and K. Severin, Inorg. Chem., 2016, 55, 4006; (c) M. Pascu, M. Marmier, C. Schouwey, R. Scopelliti, J. J. Holstein, G. Bricogne and K. Severin, Chem. Eur. J., 2014, 20, 5517.

15 (a) G. E. Zelinskii, A. S. Belov, E. G. Lebed, A. V. Vologzhanina, V. V. Novikov and Y. Z. Voloshin, Inorg. Chim. Acta, 2016, 440, 154; (b) J. Zhang, Z. Ma, H. Zhao, C. Ge, X. Wang and X. Zhang, Inorg. Chem. Commun., 2016, 65, 63; (c) E. G. Lebed, A. S. Belov, A. V. Dolganov, A. V. Vologzhanina, A. Szebesczyk, E. Gumienna-Kontecka, H. Kozlowski, Y. N. Bubnov, I. Y. Dubey and Y. Z. Voloshin, Inorg. Chem. Commun., 2013, 30, 53; (d) E. G. Lebed, A. S. Belov, A. V. Dolganov, A. V. Vologzhanina, V. V. Novikov, E. V. Kuznetsov and Y. Z. Voloshin, Inorg. Chem. Commun., 2013, 30, 57.

16 T. E. Barder, S. D. Walker, J. R. Martinelli, and S. L. Buchwald, J. Am. Chem. Soc., 2005, 127, 4685.

17 (a) S. Bivaud, S. Goeb, J.-Y. Balandier, M. Chas, M. Allain and M. Sallé, Eur. J. Inorg. Chem., 2014, 2440; (b) S. Bivaud, J.-Y. Balandier, M. Chas, M. Allain, S. Goeb and M. Sallé, J. Am. Chem. Soc., 2012, 134, 11968; (c) A. K. Bar, S. Mohapatra, E. Zangrando and P. S. Mukherjee, Chem. Eur. J., 2012, 18, 9571; (d) D. C. Caskey, T. Yamamoto, C. Addicott, R. K. Shoemaker, J. Vacek, A. M. Hawkridge, D. C. Muddiman, G. S. Kottas, J. Michel and P. J. Stang, J. Am. Chem. Soc., 2008, 130, 7620; (e) N. Fujita, K. Biradha, M. Fujita, S. Sakamoto and K. Yamaguchi, Angew. Chem. Int. Ed., 2001, 40, 1718. 


\section{Graphic for the TOC:}

Large coordination cages with unusual gyrobifastigium-like geometry were obtained by combining cis-blocked $\mathrm{Pt}^{\mathrm{II}}$ or $\mathrm{Pd}^{\mathrm{II}}$ complexes with clathrochelate-based metalloligands.

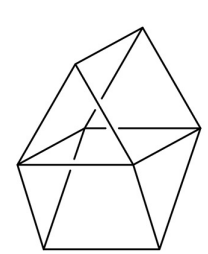

gyrobifastigium

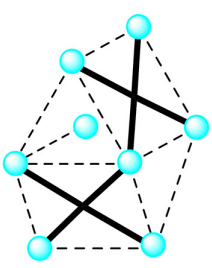

$\mathrm{M}_{8} \mathrm{~L}_{4}$

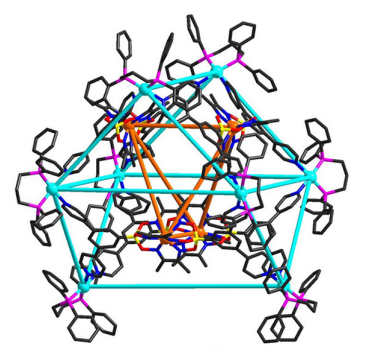

